\title{
Continuous evaluation of changes in the serum proteome from early to late stages of sepsis caused by Klebsiella pneumoniae
}

\author{
SWATHI RAJU $\mathrm{M}^{1}$, JAHNAVI $\mathrm{V}^{2}$, RATNAKAR S. KAMARAJU ${ }^{2}$, VENKATARAMAN SRITHARAN ${ }^{2}$, \\ KARTHIK RAJKUMAR ${ }^{1}$, SUMATHI NATARAJAN ${ }^{3}$, ANIL D. KUMAR ${ }^{3}$ and SANDEEPTA BURGULA ${ }^{1}$ \\ ${ }^{1}$ Department of Microbiology, Osmania University, Hyderabad, Telangana 500007; \\ ${ }^{2}$ Molecular Diagnostics and Biomarkers Department of Laboratory Medicine Global Hospitals, Hyderabad, \\ Telangana 500004; ${ }^{3}$ Department of Biochemistry, Osmania University, Hyderabad, Telangana 500007, India
}

Received August 27, 2015; Accepted January 20, 2016

DOI: $10.3892 / \mathrm{mmr} .2016 .5112$

\begin{abstract}
Serum protein profiles of patients with bacterial sepsis from the day of diagnosis until recovery/mortality were compared from early to late stages in response to severe sepsis using two dimensional electrophoresis. The proteins exhibiting changes during the course of sepsis (20-28 day mortality) were selected and identified by matrix-assisted laser desorption ionization-time of flight-tandem mass spectrometry. Among the proteins identified, haptoglobin (Hp), transthyretin (TTR), orosomucoid 1/ $\alpha 1$ acid glycoprotein (ORM1), $\alpha 1$ antitrypsin (A1AT), serum amyloid A (SAA) and S100A9 exhibited differential expression patterns between survivors $(S ; n=6)$ and non-survivors (NS; $n=6$ ), particularly during the early stages of sepsis. Expression factors (EFs), taken as the ratio between the NS and $\mathrm{S}$ during early stages, showed ratios of Hp, 0.39 ( $\mathrm{P} \leq 0.012$ ); TTR, 3.96 ( $\mathrm{P} \leq 0.03)$; ORM1, 0.69 ( $\mathrm{P} \leq 0.79$ ); A1AT, $0.92(\mathrm{P} \leq 0.87)$ and SAA, $0.69(\mathrm{P} \leq 0.01)$. S100A9, an acute phase protein, exhibited an EF ratio of $1.68(\mathrm{P} \leq 0.004)$ during the end stages of sepsis. A delayed rise in levels was observed in Hp, A1AT, ORM1, S100A9 and SAA, whereas TTR levels increased during the early stages of sepsis in NS. Analysis of inflammatory responses in the early stages of
\end{abstract}

Correspondence to: Dr Sandeepta Burgula, Department of Microbiology, Osmania University, Tarnaka, Hyderabad, Telangana 500007, India

E-mail: s_burgula@osmania.ac.in

Abbreviations: APR, acute phase response; A1AT, $\alpha 1$ antitrypsin; $\mathrm{CRP}, \mathrm{C}$ reactive protein; $\mathrm{CNTF}$, ciliary neurotrophic factor; DAMPs, damage associated molecular patterns; GO, gene ontology; Hp, haptoglobin; HBB, hemoglobin $\beta$ subunit; IL, interleukin; LPS, lipolysaccharide; MAP, kinase-mitogen activated protein kinase; NS, non-survivor; ORM 1, orosomucoid 1; PAMPs, pathogen associated molecular patterns; PCT, procalcitonin; S, survivor; SAA, serum amyloid A; SOFA, sequential organ failure assessment score; TLRs, Toll-like receptors; TNF, tumour necrosis factor; TTR, transthyretin

Key words: bacterial sepsis, acute phase proteins, two dimensional gel electrophoresis, serum proteome sepsis revealed increased mRNA expression in leukocytes of interleukin (IL)-6 (EF, 2.50), IL-10 (EF, 1.70) and prepronociceptin (EF, 1.6), which is a precursor for nociceptin in NS compared with $\mathrm{S}$, and higher Toll-like receptor-4 (EF, 0.30) levels in S compared with NS. Therefore, a weaker acute phase response in the early stages of sepsis in NS, combined with an inefficient inflammatory response, may contribute to sepsis mortality.

\section{Introduction}

The inflammatory response to a variety of systemic infections results in sepsis in susceptible individuals, wherein the mortality rate is an alarming $30-45 \%$. Sepsis constitutes $17 \%$ of all admissions to the intensive care unit, of which $45 \%$ of admissions end in fatality (1). Severe sepsis takes more lives than cardiovascular disease, breast, colon/rectal, head and neck, throat and prostate cancer combined, and the incidence of sepsis is rising by $1.5-8 \%$ annually (2-4), despite advancements in critical care support and equipment. While very little is known about the genetic susceptibility of an individual, the risk of sepsis increases due to various immunosuppressive procedures.

Several novel approaches in sepsis prophylaxis and treatment are currently in progress (4). Certain clinical trials have provided contrasting results. For example, when patients with sepsis were treated with two different monoclonal antibodies against endotoxin-HA-1A, a human antibody and E5, a murine antibody, no change in mortality was observed in patients with gram negative bacteremia (5). Animal models have also provided conflicting results when compared with human studies (6). Therefore, using an animal sepsis model may not provide conclusive evidence for human application. Immunological response to Gram-negative bacterial lipopolysaccharide (LPS) predominantly involves their interaction with Toll-like receptors (TLRs) and cluster of differentiation (CD)14 receptors present on monocytes and macrophages, which initiates the production of pro-inflammatory mediators, including interleukin (IL)-6, IL-8 and tumor necrosis factor (TNF)- $\alpha$. LPS also induces the production of acute phase response proteins by the liver. Among many known sepsis markers, serum procalcitonin (PCT) is currently the only US Food and Drug Administration approved biomarker for the diagnosis, and as an indicator, of 
the progression of sepsis, though other acute phase reactants, including $\mathrm{C}$ reactive protein (CRP) and serum amyloid $\mathrm{A}$ (SAA) protein, are also in use. Several biomarkers are known to be elevated in sepsis (7), although the exact biochemical function and etiology of their overexpression remain unknown. Host immunological response to sepsis is nuanced, and varies in both innate and adaptive responses, which makes diagnosis and therapy a challenge for individuals at risk of mortality.

The diagnosis of sepsis and evaluation of its severity is complicated by the highly variable and non-specific nature of the signs and symptoms of sepsis (8). Early diagnosis and prediction of the severity of sepsis is very important, thereby increasing the possibility of starting timely and specific treatment $(9,10)$. Previous studies have shown gender-based variation in the pattern of expression of acute phase proteins and sepsis-associated mortality (11), wherein mutually opposing observations have been made, which make adjustments with concurrent data while generalizing observations (12). A previous study involving elderly patients revealed that sepsis mortality was independent of gender; however, this was correlated with elevated $17 \beta$-estradiol in both genders, with elevated progesterone in males and elevated testosterone in females (13). An increased risk of acquiring sepsis in surgery patients with higher TNF- $\alpha$ levels due to polymorphism in the NcoI region of the TNFB gene has been reported $(14,15)$. However, a generalization in this regard requires study of a larger cohort. Recent advances in understanding sepsis involve various sepsis models to diagnose susceptibility towards sepsis, however, a clear correlation requires a broader and deeper analysis of sepsis response proteins. To address the issue, Kalenka et al (16) analyzed the serum proteome of sepsis patients and successfully identified differences between the proteome of survivors ( $\mathrm{S}$ ) and non-survivors (NS) at the end of 28 days from the onset of sepsis (16). Similarly, Su et al (17) studied urinary proteomics of sepsis patients during the 28 days from the onset of sepsis (17). These studies have made significant contributions to the understanding of serum protein dynamics to assess the differential changes associated with S and NS of sepsis. The present study is a prospective observational longitudinal study, where serum proteome dynamics from early until late stages of sepsis were analyzed in $\mathrm{S}$ and NS, from the onset of sepsis as indicated by PCT levels.

Since sepsis has a higher incidence in males, and females appear to differ in responses due to hormonal variations, the present study used adult human male samples for homogeneity. The goal of the present study was to target differentially expressed proteins while comparing S and NS, which may be useful, particularly in the early stages to devise strategies to improve chances of patient survival. The present study focused on serum proteome profiles at different phases of sepsis in Indian adult male patients suffering with bacterial sepsis, particularly $K$. pneumoniae, to eliminate further possibility of heterogeneity in sampling, which may assist with understanding changes in serum acute phase proteins under given conditions, and can be later used to monitor and devise methods of patient-specific sepsis management.

\section{Materials and methods}

Patients and samples. Blood samples from adult male patients ( $\mathrm{n}=12 ; \mathrm{S}$ and NS $=6$ each) diagnosed with sepsis were procured from Global Hospitals (Lakdi-ka-pul Hyderabad, India; Table I). The patients were carefully monitored up until mortality at day 20-28, and samples were collected daily from the day of clinical diagnosis (onset) until recovery, in the case of $\mathrm{S}$, and $24 \mathrm{~h}$ prior to mortality in the case of NS. Criteria for selection of male patients showing signs of severe sepsis or septic shock (endotoxemia) were based on patient serum PCT levels and acute physiology and chronic health evaluation II (APACHE II) scores (Table I). APACHE II is a severity-of-disease classification system (18), one of several ICU scoring systems. It is applied within $24 \mathrm{~h}$ of the admission of a patient to an intensive care unit: An integer score from 0 to 71 is computed based on several measurements; higher scores correspond to more severe disease and a higher risk of death. The APACHE II scoring system has been widely accepted as a measure of illness severity; it has been demonstrated to accurately stratify risk of death in a wide range of disease states, and in different clinical settings (19). Blood samples from healthy males $(n=6)$ were collected with their consent as reference controls. Serum was isolated from blood samples of both patients and healthy controls for further analysis. Whole blood was collected separately from the identical male patients $(S=6 ; N S=6)$ at early stages (within $24 \mathrm{~h}$ of sepsis diagnosis) in EDTA-K3 containing tubes for RNA extraction and reverse transcription-quantitative polymerase chain reaction (RT-qPCR) analysis. Exclusion criteria for sample selection were being $<18$-years-old and $>75$-years-old, patients who were lost at follow-up, patients with previous medical history of anti-inflammatory drug treatment, chemotherapy and glucocorticoid therapy. Burns patients, subjects with liver diseases, cardiovascular diseases and organ transplant recipients were not enrolled. Samples from each individual patient were collected with the informed consent of the patient or family, and the present study was approved by the institutional ethical committee.

Two dimensional electrophoresis. Serum samples for each day from the onset of sepsis until the recovery/death of each patient $(n=6)$ and individual controls $(n=6)$ were subjected to Albumin depletion, according to the manufacturer's protocol (Aurum ${ }^{\mathrm{TM}}$ Affi-Gel ${ }^{\circledR}$ Blue mini kits and columns; Bio-Rad Laboratories, Inc., Hercules, CA, USA). Complete albumin depletion was confirmed by $10 \%$ sodium dodecyl sulfate-polyacrylamide gel electrophoresis (SDS-PAGE). The albumin-depleted elutes were subsequently diluted with ice-cold acetone and subjected to acetone precipitation at $15,000 \mathrm{x} \mathrm{g}$ at $4^{\circ} \mathrm{C}$ for $10 \mathrm{~min}$. The pellets obtained were washed with $1 \mathrm{ml}$ acetone and allowed to air-dry. The pellets were subsequently resuspended in $75 \mu 1$ rehydration sample buffer, containing $4 \mathrm{M}$ urea, $2 \% \mathrm{CHAPS}, 1 \mathrm{mM}$ dithiothreitol, 0.2\% Biolyte, 3/10 ampholytes (Bio-Rad laboratories, Inc.) and traces of Bromophenol blue dye. Once the pellets were completely dissolved in rehydration sample buffer, the total protein content in resuspended sample was estimated using Bradford protein assay (Sigma-Aldrich, St. Louis, MO, USA). A total of $500 \mu \mathrm{g}$ protein was applied to $11 \mathrm{~cm}(\mathrm{pH} \mathrm{3-10)}$ immobilized $\mathrm{pH}$ gradient (IPG) strips (Bio-Rad Laboratories, Inc.) and isoelectric focusing was performed using a Protean IEF unit, according to the manufacturers protocol (Bio-Rad Laboratories, Inc.). The IPG strips were subsequently separated 
Table I. Clinical characteristics of sepsis subjects.

Patient details

Characteristic

\section{Survivor}

$(n=6)$

$50 \pm 2$

Male

Gender

Median white blood cell count $/ \mathrm{mm}^{3}$

Median serum procalcitonin

APACHE II (median)

Pathogens detected in culture (median)
14,380

$3.99 \pm 2$

26

K.p
Non-survivor $(\mathrm{n}=6)$

$71 \pm 2$

Male

1,850

$2.58 \pm 2$

30

K.p

APACHE II, acute physiology and chronic health evaluation II; K.p, Klebsiella pneumoniae; n, number of patients.

by $9-14 \%$ gradient SDS-PAGE at $16 \mathrm{~mA}$ for the stacking gel and $24 \mathrm{~mA}$ for the resolving gel. Following electrophoresis, the gels were fixed in a solution of $50 \%$ methanol and $10 \%$ glacial acetic acid for $1 \mathrm{~h}$ and were subsequently stained with colloidal Coomassie blue stain for image analysis.

Image analysis. The gel images were analyzed using Image Master 2D Platinum software (version 7.0; GE Healthcare Bio-Sciences, Pittsburgh, PA, USA). Control gels of healthy subjects $(n=6)$ were analyzed individually and normalized to be used as the reference gel. The daily sample for S and NS was analyzed in duplicate to identify spots with percentage volume variation. Duplicates of each day were combined to give a single representative gel and analyzed again to increase the reproducibility and reduce the error rate of analysis. The spots were compared for percentage volume variations.

In-gel trypsin digestion. The spots of interest were excised and washed with a $1: 1$ ratio of $50 \mathrm{mM}$ ammonium bicarbonate and acetonitrile for $15 \mathrm{~min}$. Following two separate washes with ammonium bicarbonate and acetonitrile, a final wash was performed with acetonitrile until the gel pieces were opaque. The acetonitrile was discarded and the gel pieces were vacuum-dried. Diluted trypsin was added to the gel pieces and incubated for $1 \mathrm{~h}$ at room temperature. The excess trypsin was removed and the pieces were incubated overnight with $25 \mathrm{mM}$ ammonium bicarbonate at $37^{\circ} \mathrm{C}$. The digested extract was collected and vacuum centrifuged to concentrate the extract, which was subsequently used for matrix-assisted laser desorption ionization-time of flight (MALDI-TOF; Bruker Daltonics, Leipzig, Germany) analysis.

MALDI-TOF analysis. An $\alpha$-cyano-4-hydroxycinnamic acid (HCCA) matrix $(5 \mathrm{mg} / \mathrm{ml})$ was prepared in $70 \%$ acetonitrile and $30 \% \quad 0.1 \%$ trifluoroacetic acid. The trypsin-digested extract was subsequently mixed with HCCA matrix in a 1:1 ratio and $\sim 2 \mu$ l matrix-sample mix was spotted onto an anchor chip and ground steel plate (Bruker Daltonics). Once dried, the plates were loaded onto a MALDI TOF-mass spectrometer (MS; Bruker Daltonics) at the Central Facilities for Research and Development (Osmania University, Hyderabad, India). Spectra were obtained in the reflectron mode (mass range,
500-3,000 Da; $20 \mathrm{keV}$ accelerating voltage; averaging 500 laser shots/spectrum) using a Bruker Autoflex III MALDI-TOF/TOF spectrometer (Bruker Daltonics). The spectra were analyzed with Flex Analysis software (version 3.3; Bruker Daltonics) and Biotools software (version 3.2; Bruker Daltonics), with the following parameters: Signal-to-noise threshold, 6; mass exclusion tolerance, $0.75 \mathrm{~m} / \mathrm{z}$; maximal number of peaks, 100 ; quality factor threshold, 50; monoisotopic peaks (Adduct: H). Matrix and/or auto-proteolytic trypsin peaks, or known contaminant ions were excluded. Bioinformatics data mining was performed using the Mascot platform (http://www.matrixscience.com). The resulting peptide mass lists were queried in the Swiss Port 2013_02 database (539,165 sequences; 191,456,931 residues). The following criteria were used for search parameters: Taxonomy, Homo sapiens (human); significant protein Molecular Weight Search score at $\mathrm{P}<0.05,1$ missed cleavage site allowed; $1+$ peptide charges allowed; trypsin as enzyme; $80-100$ ppm as precursor tolerance; carboxymethylation of Cys as global modification and oxidation of methionine as variable modification. The protein score was calculated as $-10 x \log (\mathrm{P})$, where $\mathrm{P}$ is the probability that the observed match is a random event. A protein score of $\geq 56$ was considered statistically significant $(\mathrm{P}<0.05)$. Further analysis and function-based classification of the identified proteins were performed using the protein centre software version 3.10 (Thermo Fisher Scientific, Inc., Waltham, MA, USA).

Statistical analysis. Comparisons between groups (S and NS sepsis patients) were performed using either a paired Student's t-test and/or a Mann Whitney U test, using GraphPad Prism (version 6.05; GraphPad Software,. Inc., San Diego, CA, USA). The expression factors (EFs) are expressed as the mean \pm standard error of the mean. $\mathrm{P} \leq 0.05$ was considered to indicate a statistically significant difference.

$R T$ - $q P C R$ analysis. Blood samples from sepsis patients were obtained and the total RNA was extracted using Total RNA spin columns (Yeastern Biotech, Co., Ltd., Taipei, Taiwan) and treated with RNase-free DNase (Macherey-Nagel, Inc., Düren, Germany). A total of $\sim 5 \mu \mathrm{g}$ RNA was reverse-transcribed using oligo (dT) primers and reverse transcriptase (Thermo Fisher Scientific, Inc.). qPCR was performed on the cDNA samples 
Table II. List of primer sequences for analyzing mRNA levels in patients with sepsis.

\begin{tabular}{lll}
\hline Gene & \multicolumn{1}{c}{ Right primer (5'-3') } & \multicolumn{1}{c}{ Left primer (5'-3') } \\
\hline Haptoglobin & CATAGCCATGTGCAATCTCG & AGAGGCAAGACCAACCAAGA \\
S100A9 & TCAGCATGATGAACTCCTCG & GGAATTCAAAGAGCTGGTGC \\
Transthyretin & AGCCGTGGTGGAATAGGAG & CTTACTGGAAGGCACTTGGC \\
Serum amyloid A & CCCTTTTGGCAGCATCATAG & AGCCGAAGCTTCTTTCGTT \\
$\alpha 1$ antitrypsin & ACGAGACAGAAGACGGCATT & ATATTCACCAGCAGCCTCCC \\
Orosomucoid 1 & CCTCCTCCTGTTTCCTCTCC & AGACGACCAAGGAGCAACTG \\
Interleukin 6 & CTGCAGCCACTGGTTCTGT & CCAGAGCTGTGCAGATGAGT \\
Toll-like receptor 4 & GCCTCAGGGGATTAAAGCTC & GCCTCAGGGGATTAAAGCTC \\
Interleukin 10 & GCCACCCTGATGTCTCAGTT & GTGGAGCAGGTGAAGAATGC \\
Prepronociceptin & GAGACTGAGCAGCAGCAGGT & TATGCTGGTGTGGCTGAGAA
\end{tabular}

(2 $\mu$ l) using Faststart universal SYBR Green master (Roche Diagnostics, Indianapolis, IN, USA) with 10 pmol forward and reverse primers of six protein genes obtained employing Primer Depot (Table II). Melting temperatures were set as per primer sets used with rest of the PCR conditions. Gene expression was calculated using the $2^{-\Delta \Delta C q}$ method, where $\beta$-actin gene was used as the reference housekeeping gene.

\section{Results}

Identification of differentially expressed proteins in $S$ and NS of sepsis. Albumin-depleted serum samples from sepsis patients were separated by 2D gel electrophoresis and 2D gel image analysis was performed (Fig. 1). Protein spots representing specific proteins exhibiting an increased or decreased percentage volume and intensity were matched to the corresponding spot in the reference gel (control serum). The proteins exhibiting differential volume percentage with respect to patients with sepsis were then matched between $\mathrm{S}$ and NS from the day of onset until recovery/mortality. Approximately 300 spots were analyzed in each gel. The analysis resulted in the identification of 30 differentially expressed spots between S and NS. Identification of the spots by MALDI-TOF demonstrated 12 spots with a significant MS/MS score (Table III). Since normalized relative volumes of a spot (\%) are independent of variations due to protein loading and staining, the average of the normalized volume percentage of each spot for $n=6$ patients in each group and $\mathrm{n}=6$ controls were used to calculate the EF of differentially expressed proteins. The NS:S ratio was calculated to demonstrate the fold-change in protein expression in NS compared with $\mathrm{S}$ from onset (day of diagnosis) until recovery/mortality, and early stages of sepsis 24 h-day 3 (Table IV). Haptoglobin (Hp; spot 229, $\mathrm{P}<0.012 ; \alpha 1$ antitrypsin (A1AT), orosomucoid 1/ $\alpha 1$ acid glycoprotein (ORM1) and S100A9 ( $\mathrm{P}<0.004)$, and serum amyloid A (SAA) exhibited a $\geq 1.5$ fold increase, whereas transthyretin (TTR) (spot 237, P $<0.03$; and Hp (spot 401, $\mathrm{P}<0.005$ ) exhibited a $\geq 1$ fold decrease, from the early stages until mortality in NS (Fig. 2).

Biological function and protein network analysis. Cellular and biological functions of the six differentially expressed proteins were analyzed, where gene ontology slim analysis data of differentially expressed proteins in sepsis were obtained using mappings from the gene ontology (GO) consortium website (http://geneontology.org), shown in (Fig. 3). These proteins were identified to possess mostly cytoplasmic (23.5\%) and extracellular functions (35.2\%). Their biological functions predominantly involved the regulation of biological processes (14.6\%), response to stimulus (14.6\%), defence response (12.1\%) and transport (12.1\%). The present study sought to identify any possible network interactions between identified proteins using GeneMANIA 3.1.2.6 software (http://www.genemania.org) at the genomic and proteomic level, where GO based weighting was applied to detect maximum connectivity between the input genes, based on their biological process, molecular function and cellular component-based function. All six proteins, S100A9, SAA, Hp, TTR, SERPINA1, and ORM, were shown to be interacting closely in a protein interaction network, indicating co-expression of $91.34 \%$ and co-localization of $8.66 \%$, where expression was calculated as the Pearson correlation coefficient (Fig. 4).

Analysis of mRNA expression levels. RT-qPCR analysis of the mRNA isolated from whole blood of six patients revealed a $\geq 2$ fold increase in mRNA expression levels (NS:S fold change) of acute phase proteins, S100A9 (2.13), TTR (2.86), SAA (1.84), A1AT (1.4), ORM1 (1.68; P $\leq 0.05)$ and inflammatory markers, interleukin (IL)-6 (2.5), IL-10 (1.70), prepronociceptin (PPN; 1.6; all $\mathrm{P} \leq 0.0001$ during early stages). By contrast, Hp (0.59) and Toll-like receptor 4 TLR4 (0.30) exhibited decreased levels during early stages in NS (Figs. 5 and 6). Hp (protein, 0.59; mRNA, 0.62; P $\leq 0.05$ ) and TTR (protein, 3.9; mRNA, 2.86; $\mathrm{P} \leq 0.05$ ) showed a correlation between protein and mRNA expression levels during the early stages, whereas the other genes exhibited no significant correlation.

\section{Discussion}

An emphasis on the identification of differentially expressed proteins during the early stages of sepsis is useful in identification of marker(s) for predicting potential NS. The ratio of male patients admitted with bacterial sepsis dominated female patients during the present study; hence, the present study 
Table III. MALDI-TOF analysis of proteins differentially expressed in sepsis survivors and non-survivors.

\begin{tabular}{|c|c|c|c|c|c|c|}
\hline Spot ID & $\begin{array}{l}\text { Protein } \\
\text { identified }\end{array}$ & $\mathrm{pI}$ & $\begin{array}{l}\text { Mol. Wt. } \\
\text { (kDa) }\end{array}$ & $\begin{array}{l}\text { Mascot } \\
\text { score }\end{array}$ & $\begin{array}{c}\text { Accession } \\
\text { number and } \mathrm{ID}^{\mathrm{a}}\end{array}$ & $\begin{array}{l}\text { Attributes } \\
\text { (half-life) }\end{array}$ \\
\hline F3 & $\alpha 1$ acid glycoprotein & 4.9 & 49 & 65 & P02763 & $\begin{array}{l}\text { Acute phase protein, } \\
\text { elevated in } \\
\text { inflammation ( } 5 \text { days) }\end{array}$ \\
\hline 237 & $\begin{array}{l}\text { Transthyretin } \\
\text { (prealbumin) }\end{array}$ & 5.5 & 15 & 66 & $\begin{array}{l}\text { P02766, } \\
\text { TTHY_HUMAN }\end{array}$ & $\begin{array}{l}\text { Negative acute phase } \\
\text { protein }(12-24 \mathrm{~h})\end{array}$ \\
\hline 246 & S100A9 & 5.7 & 13 & 70 & $\begin{array}{l}\text { P06702, } \\
\text { S10A9_HUMAN }\end{array}$ & $\begin{array}{l}\text { Prominent role in the } \\
\text { regulation of } \\
\text { inflammatory } \\
\text { processes and immune } \\
\text { response }(5 \mathrm{~h})\end{array}$ \\
\hline 287 & $\begin{array}{l}\text { Hemoglobin } \\
\text { subunit } \beta\end{array}$ & 7.6 & 14 & 59 & $\begin{array}{l}\text { P68871, } \\
\text { HBB_HUMAN }\end{array}$ & $\begin{array}{l}\text { Coagulation and } \\
\text { complement pathway }\end{array}$ \\
\hline 401 & Haptoglobin & 5.8 & 45 & 63 & $\begin{array}{l}\text { P00738, } \\
\text { HPT_HUMAN }\end{array}$ & $\begin{array}{l}\text { Acute phase protein } \\
\text { ( } 3.5-5 \text { days unbound; } \\
30 \text { min bound) }\end{array}$ \\
\hline 228 & Haptoglobin & 5.2 & 23 & 67 & & \\
\hline 229 & Haptoglobin & 5.3 & 23 & 56 & & \\
\hline 230 & Haptoglobin & 5.9 & 23 & 82 & & \\
\hline 231 & Haptoglobin & 6.0 & 23 & 62 & & \\
\hline Spot I & $\begin{array}{l}\alpha 1 \text { antitrypsin/ } \\
\text { SERPINA1 }\end{array}$ & 5.3 & 46 & 96 & $\begin{array}{l}\text { P01009, } \\
\text { A1AT_HUMAN }\end{array}$ & $\begin{array}{l}\text { Acute phase protein } \\
\text { ( } 4.5 \text { days) }\end{array}$ \\
\hline M & $\alpha 1$ antitrypsin & 3.5 & 46 & 91 & & \\
\hline 252 & Serum amyloid A & 6.3 & 11 & 79 & $\begin{array}{l}\text { P0DJI8 } \\
\text { SAA1_HUMAN }\end{array}$ & $\begin{array}{l}\text { Positive acute phase } \\
\text { protein }(90 \mathrm{~min})\end{array}$ \\
\hline
\end{tabular}

a'Obtained from SWISS-PROT. MALDI-TOF, matrix-assisted laser desorption ionization-time of flight; Mol. Wt., molecular weight; ID, identification; $\mathrm{pI}$, isoelectric point.

Table IV. Expression factors of differentially expressed proteins identified in sepsis survivors and non-survivors from onset until recovery or fatality.

\begin{tabular}{lccc}
\hline Spot ID & $\begin{array}{c}\text { Protein identified } \\
\text { (early stages) }\end{array}$ & $\begin{array}{c}\text { NS:S ratio } \\
\text { (onset until recovery or death) }\end{array}$ & NS:S ratio \\
\hline 401 & Haptoglobin & 0.62 & 0.53 \\
229 & Haptoglobin & 0.39 & 0.51 \\
I & $\alpha 1$ antitrypsin/SERPINA1 & 0.92 & $0.005^{\mathrm{a}}$ \\
F3 & Orosomucoid 1 & 0.69 & $0.012^{\mathrm{b}}$ \\
246 & S100A9 & 1.36 & 0.03 \\
237 & Transthyretin & 3.96 & 0.72 \\
244 & Transthyretin & 1.05 & 2.03 \\
251 & Serum amyloid A & 0.69 & $0.004^{\mathrm{a}}$ \\
\hline
\end{tabular}

Expression factors were calculated as the ratio of the mean of the normalized spot volume (\%) divided by the mean control spot volume (\%). The ratio of the normalized mean \pm standard error of the mean values of the non-survivor, vs. survivor was calculated to show the fold change in protein expression in non-survivors compared with the survivors from onset (day of diagnosis) to recovery and the early stages of sepsis. $\left({ }^{\mathrm{a}} \mathrm{P}<0.01 ;{ }^{\mathrm{b}} \mathrm{P}<0.05\right)$.

was focused on an assessment of the serum protein profiles of male patients with severe bacterial sepsis. Currently, CRP and PCT are the only approved biomarkers used to monitor the progression of sepsis. PCT has a better profile as an early diagnostic marker for detection of bacteremia. Effectiveness of PCT in differentiating between Gram-positive and Gram-negative 


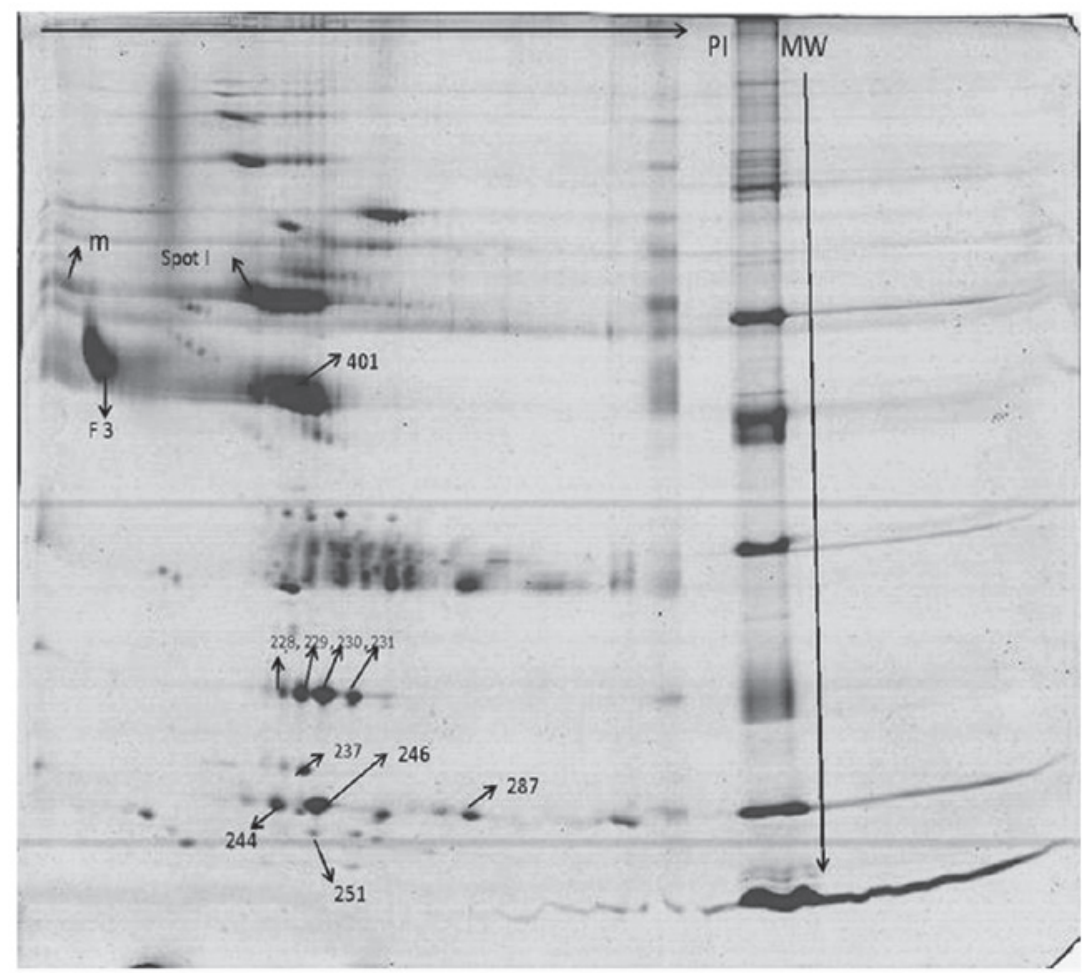

Figure 1. A representative 2D gel image of albumin-depleted serum proteins from patients with sepsis. Albumin-depleted serum samples from patients with sepsis were separated by $2 \mathrm{D}$ electrophoresis. The proteins, resolved by isoelectric focusing using $11 \mathrm{~cm}, 3-10 \mathrm{pH}$ range immobilized pH gradient strips, were separated by gradient sodium dodecyl sulfate-polyacrylamide gel electrophoresis (10-14\%). The gels were stained with Coomassie Brilliant Blue (G250) and analyzed by Image master 2D Platinum. The spots revealed to have differential spot volumes, as highlighted in the image, in survivors compared with the non-survivors were identified by matrix-assisted laser desorption ionization-time of flight. Spot I, $\alpha 1$ antitrypsin; 401/228/229/230/231, haptoglobin; F3, $\alpha 1$ acid glycoprotein $1 ; 237 / 244$, transthyretin; 246, S100A9; 287, hemoglobin subunit $\beta ; 251$, serum amyloid A.

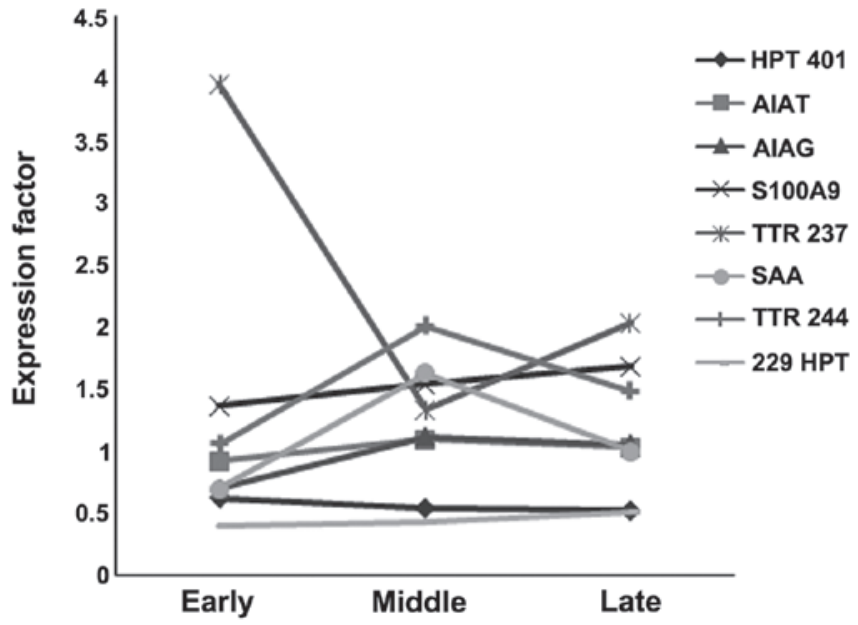

Figure 2. Graph representing changes in the levels of acute phase proteins in early, middle and late stages of sepsis in non-survivors. The ratio of the normalized mean \pm standard error of the mean values of non-survivor against survivor was calculated to show the fold change in protein levels in non-survivors compared with survivors during the early (days 1-3), middle (days 3-5) and late stages (final change in protein levels) of sepsis. HPT, haptoglobin; AIAT, $\alpha 1$ antitrypsin; AIAG, $\alpha 1$ acid glycoprotein; TTR, transthyretin, SAA, serum amyloid A.

sepsis remains unclear (20-23). Previous studies suggested that, although PCT values showed a significant difference between $\mathrm{S}$ and NS (24), only APACHE II and male gender were shown to be independent predictors of mortality due to sepsis (25).
Also, in the present study, it was observed that the PCT values revealed almost no variation in S and NS, even in the early stages (Table I). The main objective of the present study was to identify an early marker to diagnose susceptibility of a sepsis patient to mortality.

To pursue this objective, the present study first separated daily serum samples from sepsis patients by two-dimensional gel electrophoresis and compared protein profiles of S and NS. A total of 12 differentially expressed proteins were identified from the sera of sepsis patients taken from the onset until recovery/death, where $\mathrm{Hp}$ was observed in 5/12 spots, A1AT in $3 / 12$ spots and TTR in $2 / 12$ spots. The six differentially expressed proteins identified in the present study were grouped based on their family and function, as follows: i) $\alpha 1$ globulins, including A1AT, ORM1, SAA; ii) $\alpha 2$ globulins, including pre-albumin, TTR, Hp; iii) Danger-associated molecular patterns/Alarmins-Calgranulin/S100A9.

The majority of the differentially expressed proteins identified in the present study are components of inflammatory processes and the immune response, as demonstrated in protein centre analysis data utilizing the GO database (http://www.geneontology.org) and Kyoto encyclopedia of Genes and Genomes pathway (http://www.genome. $\mathrm{jp} / \mathrm{kegg} /$ pathway.html). All the six proteins are known to be involved in the host defence response and regulation of inflammatory processes (Fig. 3) (26,27). Further analysis using the GeneMANIA 3.1.2.6 software database (http://www. genemania.org) revealed close interactions between S100A9, SAA, Hp, TTR, SERPINA1 and ORM1 at the genomic 
A

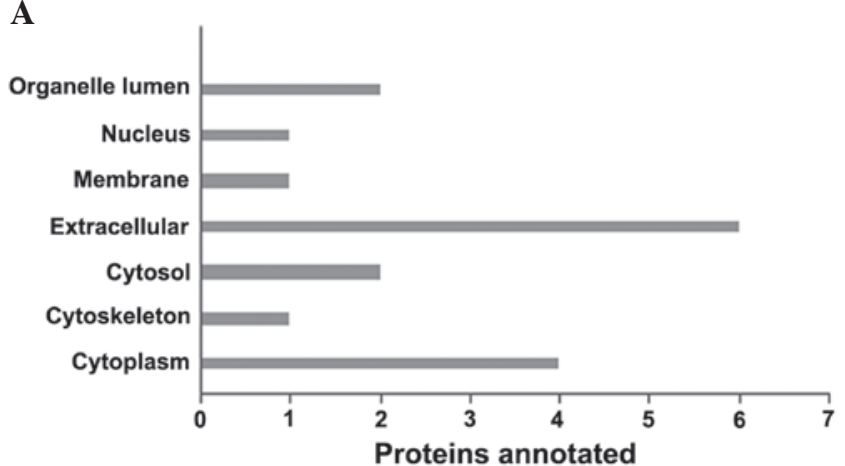

B

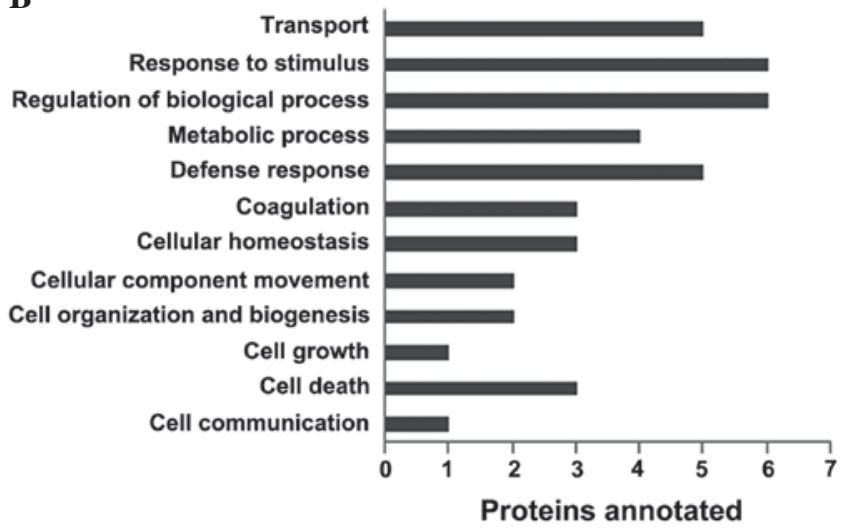

Figure 3. Gene ontology analysis of the differentially expressed proteins identified in patients with sepsis. A bar chart is shown representing (A) the cellular and (B) biological processes of serum amyloid A, transthyretin, haptoglobin, $\alpha-1$ acid glycoprotein, $\alpha-1$ antitrypsin and S100A9, identified to be differentially expressed proteins between survivors and non-survivors, as analyzed by protein centre software version 3.10 .

and proteomic level (Fig. 4). Delayed increase of proteins, including S100A9, SERPINA1, TTR, SAA and Hp, during the early stages of sepsis in NS indicated their potential role in sepsis survival (Fig. 2). Drug metabolism and drug delivery are critical in sepsis treatment. The present study demonstrated that decreased expression of drug binding proteins, including $\alpha 1$-acid glycoprotein, is correlated with the severity of sepsis.

Acute phase response leads to an increase in serum globular proteins, which are grouped into $\alpha 1$ globulins, $\alpha 2$ globulins, $\beta$-globulins secreted by the liver, and $\gamma$ globulins. The pattern of expression of $\alpha 1$ and $\alpha 2$ globulins in the present study indicated their possible role in the early stages of sepsis in male patients (Fig. 2). SAA is a precursor for amyloid A, generally shown to have an immunomodulatory effect and to be important for binding to Gram-negative bacteria, thereby facilitating their uptake by macrophages and neutrophils $(28,29)$. In the present study, low SAA levels were observed in more NS during early sepsis compared with S. The general trend was observed as a rise during the middle stages and gradual decrease towards recovery or death in sepsis. Similar results have been reported previously, where SAA levels rise within $24 \mathrm{~h}$ following infection and then tend to decrease slowly (30). However, the present study observed that SAA levels remained slightly higher in NS, even during the late stages of sepsis, when compared with S. Although certain studies suggest that SAA is a more sensitive marker for inflammatory disease (31), further investigations on its role

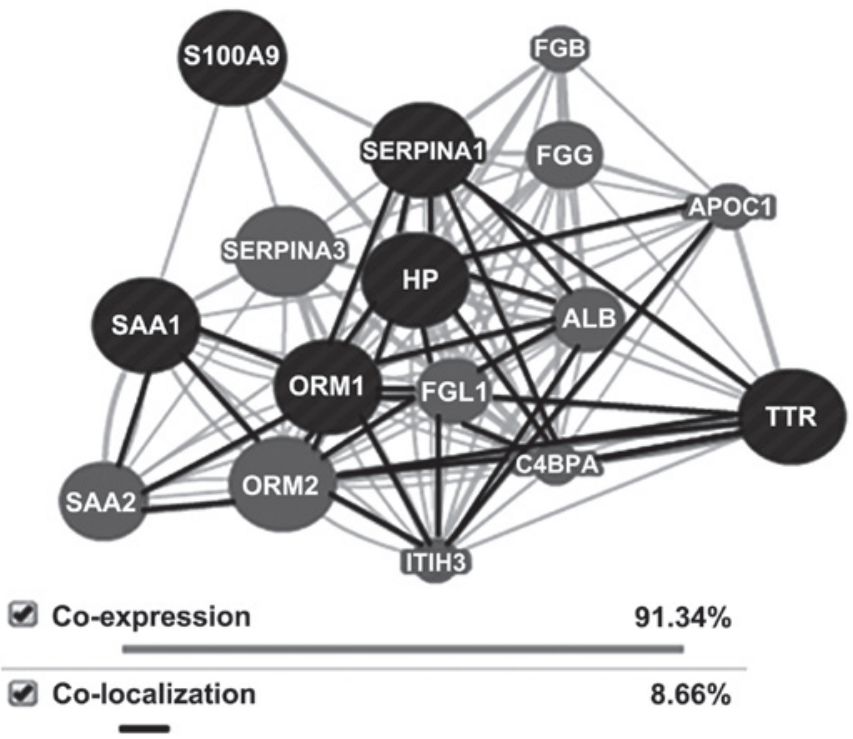

Figure 4. Network interaction between identified proteins as analyzed by GeneMANIA 3.1.2.6 software. Any possible network interaction between the differentially expressed proteins, serum amyloid A, transthyretin, haptoglobin, $\alpha-1$ acid glycoprotein, $\alpha-1$ antitrypsin and S100A9, in sepsis at the genomic and proteomic level was assessed. Grey = co-expression; dark $=$ co-localization. AIAT, $\alpha 1$ antitrypsin; ALB, albumin; APOC1, apolipoprotein $\mathrm{C} 1$; C4BPA, complement component 4 binding protein; FGB, fibrinogen $\beta$ chain; FGG, fibrinogen $\gamma$ chain; FGL1, fibrinogen-like 1; HP, haptoglobin; ITIH3, inter- $\alpha$ (glubulin) inhibitor H3; ORM, orosomucoid 1 ; SAA, serum amyloid A; SERPINA, $\alpha 1$ acid glycoprotein; TTR, transthyretin.

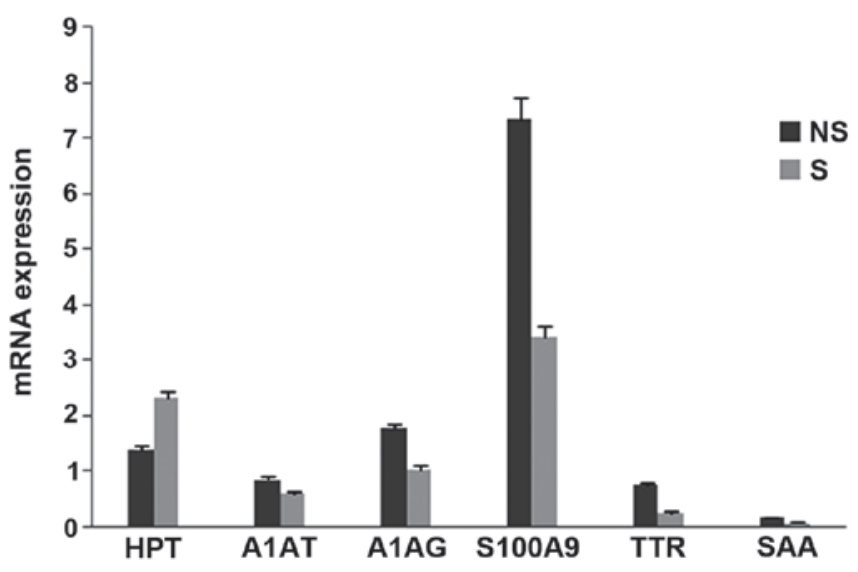

Figure 5. Graph representing changes in whole blood mRNA levels of acute phase proteins in early stages of sepsis in NS and S. Whole blood mRNA expression levels for six differentially expressed proteins were determined in the blood samples of $\mathrm{S}$ and NS by reverse transcription-quantitative polymerase chain reaction. The data are represented as mean of the $2^{-\Delta \Delta C q}$ values and the mRNA levels are expressed as the NS:S ratio (fold change) of acute phase proteins, S100A9 (2.13), TTR (2.86), SAA (1.84), A1AT (1.4), ORM1 (1.68). ( $\mathrm{P} \leq 0.05$, vs. control blood from a healthy donor). NS, non-survivors; S, survivors; HPT, haptoglobin; AIAT, $\alpha 1$ antitrypsin; AIAG, $\alpha 1$ acid glycoprotein; TTR, transthyretin, SAA, serum amyloid A.

in larger cohort-based studies would provide more insights in understanding the role of SAA as a potential marker in evaluating the severity of sepsis.

A1AT has anti-proteolytic activity and is known to inhibit particular serine proteases, which increase during inflammation. This protein serves a prominent role in the complement and coagulation pathways. The present study observed an 


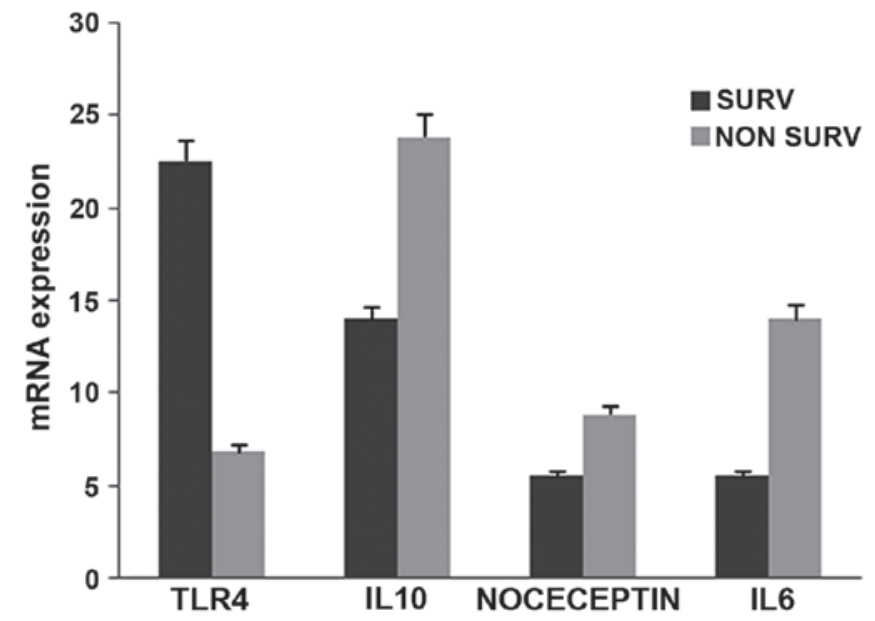

Figure 6. Graph representing changes in whole blood mRNA levels of inflammatory markers in early stages of sepsis in NS and S. Whole blood mRNA expression levels for six differentially expressed proteins were measured in the blood samples of S and NS by reverse transcription-quantitative polymerase chain reaction. The data are represented as mean of the $2^{-\Delta \Delta \mathrm{Cq}}$ values and the mRNA levels are expressed as the NS:S ratio (fold change) of the inflammatory markers, TLR4 (0.30), IL-6 (2.5), IL-10 (1.70), NOCECEPTIN (1.6). $\mathrm{P}<0.0001$, vs. control blood from healthy donor. S (SURV), survivor; NS (Non Surv), non-survivor; TLR4, Toll-like receptor 4; HPT, haptoglobin AIAT, $\alpha 1$ antitrypsin; AIAG, $\alpha 1$ acid glycoprotein; TTR, transthyretin, SAA, serum amyloid A; NOCICEPTIN, prepronociceptin.

overall rise in A1AT in NS compared with $\mathrm{S}$ from the onset until the recovery/mortality. NS exhibited a two-fold reduction in the expression of A1AT levels during the early days of sepsis compared with S. Elevated A1AT values are observed predominantly due to an acute-phase reaction to infection and inflammation, suggesting that increased protein degradation in NS leads to lower levels compared with S.

$\alpha 1$ acid glycoprotein, identified originally as orosomucoid (ORM), is a mucoprotein present in human plasma belonging to the immunoglobin superfamily $(32,33)$. Elevated levels of ORM1 are a characteristic feature of inflammatory responses $(34,35)$. The expression levels of ORM1 are known to be lower in sepsis patients who are unable to recover (36). The present study observed comparatively elevated ORM1 levels in S during early stages, followed by a fall in levels during recovery, unlike NS, where the levels gradually increased towards late stages of sepsis, mostly being stable (prior to mortality). ORM1 may be superior to CRP in terms of investigating the progress of sepsis, since increase in plasma ORM1 levels are associated with an increased mortality rate (36). Comparatively, an increase in ORM1 levels, a basic drug binding protein, in $\mathrm{S}$ indicates that drug delivery may play a critical role in sepsis survival during the early stages.

$\mathrm{Hp}$ is an acute phase protein exhibiting an $\alpha 2$ glucoprotein structure. Plasma Hp levels are used in the diagnosis of hemolytic events in addition to acute and chronic infections. Although the majority of the previous reports have shown higher levels of serum Hp in neonatal sepsis, due to its low specificity and sensitivity, its application in clinical diagnosis remains under investigation (37). It was revealed that serum Hp levels are elevated in sepsis S during the early stages of sepsis compared with NS.
TTR, also known as pre-albumin, is a thyroxine-binding protein, which also aids in the transport of vitamin A by forming a complex with retinol-binding protein (38). The present study observed elevated levels of TTR in NS during the early stages, followed by its gradual decrease towards mortality. In the present study, TTR levels remained higher from the middle until the end stages of sepsis in $\mathrm{S}$ in contrast with NS, where the levels decreased from the middle until the end stages, indicating that elevated levels of TTR may be considered relevant in monitoring sepsis survival.

The pattern recognition receptors of the innate immune response, which recognize endogenous mediators, are released in response to injury, warning the host and are termed 'Alarmins' or danger-associated molecular patterns. S100A9 or myeloid-related protein 14, is an example of an alarmin which amplifies the pro-inflammatory response through TLR4. S100A9 was observed to increase during the early stages of sepsis and remained unchanged during the middle to recovery stages in S, whereas NS exhibited increased levels towards septic shock (39). Although the biological functions of these proteins are not completely understood, they appear to depend on interactions with receptor for advanced glycation end products and TLR4. An increase in S100A9-like alarmins in serum act as indicator of sepsis, and its delayed increase in NS may represent the severity of sepsis.

Gene expression profiling to identify any possible significant correlation between the mRNA and protein expression levels of the six differentially expressed proteins was performed using qPCR, where Hp and TTR exhibited a correlation between protein and mRNA levels in the sepsis patients, while the other four proteins showed no significant correlation. The comparison signifies limited correlation between mRNA and protein expression levels, which may be attributed to the varied half-lives of proteins, the post-translational modifications involved in turning mRNA into proteins $(40,41)$ and, finally, differing experimental conditions. All this may limit the correlation between mRNA and protein expression levels. Several previous studies have demonstrated that little or no correlation is established between mRNA and protein levels $(42,43)$. Protein synthesis, degradation and also protein turnover may vary significantly, depending on a number of different conditions (44). Significant heterogeneity is present, even within similarly functioning proteins (45). For example, the $\mathrm{Hp}$ genotype exists in isoforms Hp1-1, Hp 2-1 and Hp 2-2, and their prevalence is observed to vary according to geographic distribution; additionally, Hp1-1, containing more $\alpha \beta$ chains, was shown to bind more hemoglobin compared with the other two types (46).

Proinflammatory cytokines, IL1- $\beta$, IL6 and TNF, and anti-inflammatory cytokines, IL10, IL-1 receptor antagonists and soluble TNF receptors, serve an important role in mediating sepsis. IL-6 is a cytokine that is released by macrophages, endothelial cells or fibroblasts, and appears to be the most efficient stimulator of the production by the liver of the acute phase proteins in response to IL-1 and/or TNF $\alpha$. IL10 was reported to be high in NS and a high IL-10:TNF- $\alpha$ ratio was associated with mortality, indicating that the anti-inflammatory cytokine, IL-10, is a predictor for severity and fatal outcome $(47,48)$. Increased IL-10 levels are also known to be associated with a positive outcome in sepsis, and also as a good marker to 
study the severity of sepsis, as suggested by studies based on murine models. By contrast, IL-10 knockout mice revealed no difference in the survival rate. In the present study, increased IL-10 and IL-6 expression was observed in NS of sepsis. This revealed no effect on the outcome of the patient.

Nociceptin/orphanin FQ (N/OFQ) is a 17-amino-acid opioid-associated peptide, which is produced from proteolytic cleavage of PPN/orphanin FQ (PPN/OFQ). Activation of nociceptin-NOP signaling is known to induce production of inflammatory mediators, which leads to altered expression of cytokines. Human peripheral blood mononuclear cells and polymorphonuclear leukocytes express mRNA transcripts encoding both PPN/OFQ and the NOP (nociceptin receptor). LPS binds its receptors CD14, TLR4 and myeloid differentiation protein- 2 on immune cells, and is known to rapidly induce the mRNA expression of PPN/OFQ (49-51), which is observed to be reversed on inhibiting TLR4. To determine the relevance of TLR4 and PPN/OFQ in bacterial sepsis, in the present study their mRNA expression levels in patient blood samples were screened for in early sepsis. Compared with $\mathrm{S}$, the expression levels of TLR4 were four-fold lower in NS samples, whereas PPN/OFQ levels were 0.38 -fold higher in NS, possibly indicating increased conversion of the precursor into N/OFQ. This observation confirms previous findings, where Williams et al (52) identified higher nociceptin levels in critically ill patients who underwent gastrointestinal surgery.

Since Asians respond differently to most diseases when compared with other races, a definite understanding of immunological status and pathogenesis of sepsis in these populations is indispensable. The present study provided a brief insight into possible differential expression and correlation among the proteins involved in sepsis in terms of survivability. It is important to have a laboratory method which is rapid, specific and sensitive enough to predict sepsis mortality at an early stage. A biomarker-based algorithm (53) would become predictive if a population-specific genetic marker, which predisposes the patients to sepsis, is identified.

\section{Acknowledgements}

The present study was supported by an OU-DST-PURSE programme grant [Project Sanction No. A-12 (category 2A)]. The authors would like to thank Global Hospitals (Hyderabad, India) for their support in the project. The authors would also like to thank Professor Surya S Singh (Osmania University, Hyderabad, India), for providing the logistic support for the study. University Grants Commission (New Delhi, India), provided a fellowship to Ms. Swathi Raju. M. Mr. Karthik Rajkumar has a project fellowship under the OU-DST-PURSE programme. Finally, the authors would like to thank Dr Manjula Bhanoori (Department of Biochemistry, Osmania University, Hyderabad, India) for her valuable suggestions during manuscript preparation.

\section{References}

1. Todi S: Sepsis: New horizons. Ind J Crit Care Med 14: 1-2, 2010

2. Angus DC, Linde-Zwirble WT, Lidicker J, Clermont G, Carcillo J and Pinsky MR: Epidemiology of severe sepsis in the United States: Analysis of incidence, outcome and associated costs of care. Crit Care Med 29: 1303-1310, 2001.
3. Martin GS, Mannino DM, Eaton S and Moss M: The epidemiology of sepsis in the United States from 1979 through 2000. New Eng J Med 348: 1546-1554, 2003.

4. Carvalho PR and Trotta Ede A: Advances in sepsis diagnosis and treatment. J Pediatr (Rio J) 79 (Suppl 2): S195-S204, 2003.

5. Marra MN, Thornton MB, Snable JL, Wilde CG and Scott RW: Endotoxin-binding and -neutralizing properties of recombinant bactericidal/permeability-increasing protein and monoclonal antibodies HA-1A and E5. Crit Care Med 22: 559-565, 1994.

6. Cohen J: Adjunctive therapy in sepsis: A critical analysis of the clinical trial programme. Brit Med Bull 55: 212-225, 1999.

7. Riedemann NC, Guo RF and Ward PA: The enigma of sepsis. J Clin Invest 112: 460-467, 2003.

8. Bone RC, Fisher CJ Jr, Clemmer TP, Slotman GJ, Metz CA and Balk RA: Sepsis syndrome: A valid clinical entity. Methylprednisolone severe sepsis study group. Crit Care Med 17: 389-393, 1989.

9. Kumar A, Roberts D, Wood KE, Light B, Parrillo JE, Sharma S, Suppes R, Feinstein D, Zanotti S, Taiberg L, et al: Duration of hypotension before initiation of effective antimicrobial therapy is the critical determinant of survival in human septic shock. Crit Care Med 34: 1589-1596, 2006.

10. Zambon M, Ceola M, Almeida-de-Castro R, Gullo A and Vincent JL: Implementation of the surviving sepsis campaign guidelines for severe sepsis and septic shock: We could go faster. J Crit Care 23: 455-460, 2008.

11. Schröder J, Kahlke V, Staubach KH, Zabel P and Stüber F: Gender differences in human sepsis. Arch Surg 133: 1200-1205, 1998.

12. Pietropaoli AP, Glance LG, Oakes D and Fisher SG: Gender differences in mortality in patients with severe sepsis and septic shock. Gender Med 7: 422-437, 2010.

13. Angstwurm MW, Gaertner R and Schopohl J: Outcome in elderly patients with severe infection is influenced by sex hormones but not gender. Crit Care Med 33: 2786-2793, 2005.

14. Schröder J, Kahlke V, Book M and Stüber F: Gender differences in sepsis: Genetically determined? Shock 14: 307-310; discussion 310-313, 2000.

15. Baghel K, Srivastava RN, Chandra A, Raj S, Goel SK, Pant AB and Agrawal J: Tumor necrosis factor- $\beta$ Ncol polymorphism and susceptibility to sepsis following major elective surgery. Surg Infect (Larchmt) 15: 213-20, 2014.

16. Kalenka A, Feldmann RE Jr, Otero K, Maurer MH, Waschke KF and Fiedler F: Changes in the serum proteome of patients with sepsis and septic shock. Anesth Analg 103: 1522-1526, 2006.

17. Su L, Cao L, Zhou R, Jiang Z, Xiao K, Kong W, Wang H, Deng J, Wen B, Tan F, et al: Identification of novel biomarkers for sepsis prognosis via urinary proteomic analysis using iTRAQ labeling and 2D-LC-MS/MS. PloS One 8: e54237, 2013.

18. Knaus WA, Draper EA, Wagner DP and Zimmerman JE: APACHE II: A severity of disease classification system. Crit Care Med 13: 818-829, 1985.

19. Markgraf R, Deutschinoff G, Pientka L and Scholten T: Comparison of acute physiology and chronic health evaluations II and III and simplified acute physiology score II: A prospective cohort study evaluating these methods to predict outcome in a German interdisciplinary intensive care unit. Crit Care Med 28: 26-33, 2000.

20. Wiersinga WJ, Leopold SJ, Cranendonk DR and van der Poll T: Host innate immune responses to sepsis Virulence: 5: 36-44, 2014.

21. Becker KL, Snider R and Nylen ES: Procalcitonin assay in systemic inflammation, infection and sepsis: Clinical utility and limitations. Crit Care Med 36: 941-452, 2008.

22. Sakr Y, Sponholz C, Tuche F, Brunkhorst F and Reinhart K: The role of procalcitonin in febrile neutropenic patients: Review of the literature. Infection 36: 396-407, 2008.

23. Kim KE and Han JY: Evaluation of the clinical performance of an automated procalcitonin assay for the quantitative detection of bloodstream infection. Korean J Lab Med 30: 153-159, 2010.

24. Pettilü V, Hynninen M, Takkunen O, Kuusela P and Valtonen M: Predictive value of procalcitonin and interleukin 6 in critically ill patients with suspected sepsis. Intensive Care Med 28: 1220-1225, 2002.

25. Ruiz-Alvarez MJ, Garcia-Valdecasas S, De Pablo R, Sanchez Garcia M, Coca C, Groeneveld TW, Roos A, Daha MR and Arribas I: Diagnostic efficacy and prognostic value of serum procalcitonin concentration in patients with suspected sepsis. J Intens Care Med 24: 63-71, 2009. 
26. Fischer CL, Gill C, Forrester MG and Nakamura R: Quantitation of 'acute-phase proteins' postoperatively. Value in detection and monitoring of complications. Am J Clin Pathol 66: 840-846, 1976.

27. Gruys E, Toussaint MJ, Niewold TA and Koopmans SJ: Acute phase reaction and acute phase proteins. J Zhejiang Univ Sci B 6 : 1045-1556, 2005.

28. Hari-Dass R, Shah C, Meyer DJ and Raynes JG: Serum amyloid A protein binds to outer membrane protein $\mathrm{A}$ of gram-negative bacteria. J Biol Chem 280: 18562-18567, 2005.

29. Larson MA, Weber A, Weber AT and McDonald TL: Differential expression and secretion of bovine serum amyloid A3 (SAA3) by mammary epithelial cells stimulated with prolactin or lipopolysaccharide. Vet Immunol Immunop 107: 255-264, 2005.

30. Cicarelli LM, Perroni AG, Zugaib M, de Albuquerque PB and Campa A: Maternal and cord blood levels of serum amyloid A, C-reactive protein, tumor necrosis factor-alpha, interleukin-lbeta and interleukin-8 during and after delivery. Mediat Inflamm 2005: 96-100, 2005.

31. Gabay $C$ and Kushner I: Acute-phase proteins and other systemic responses to inflammation. N Eng J Med 340: 448-454, 1999.

32. Weimer HE and Winzler RJ: Comparative study of orosomucoid preparations from sera of six species of mammals. Proc Soc Exp Biol Med 90: 458-60, 1955.

33. Whicher JT: BCR/IFCC reference material for plasma proteins (CRM 470). Community bureau of reference. International Federation of Clinical Chemistry. Clin Biochem 31: 459-465, 1998.

34. Dinarello CA: Cytokines as mediators in the pathogenesis of septic shock. Curr Top Microbiol Immunol 216: 133-165, 1996.

35. Henry OF, Blacher J, Verdavaine J, Duviquet M and Safar ME: Alpha 1-acid glycoprotein is an independent predictor of in-hospital death in the elderly. Age Ageing 32: 37-42, 2003.

36. Barroso-Sousa R, Lobo RR, Mendonça PR, Memória RR Spiller F, Cunha FQ and Pazin-Filho A: Decreased levels of alpha-1-acid glycoprotein are related to the mortality of septic patients in the emergency department. Clinics (Sao Paulo) 68 $1134-1139,2013$.

37. Langlois MR and Delanghe JR: Biological and clinical significance of haptoglobin polymorphism in humans. Clin Chem 42 1589-600, 1996.

38. Cynober L, Prugnaud O, Lioret N, Duchemin C, Saizy R and Giboudeau J: Serum transthyretin levels in patients with burn injury. Surgery 109: 640-644, 1991.

39. Payen D, Lukaszewicz AC, Belikova I, Faivre V, Gelin C, Russwurm S, Launay JM and Sevenet N: Gene profiling in human blood leucocytes during recovery from septic shock. Intens Care Med 34: 1371-1376, 2008

40. Szallasi Z: Genetic network analysis in light of massively parallel biological data acquisition. Pac Symp Biocomput 5-16, 1999.
41. Cho RJ, Campbell MJ, Winzeler EA, Steinmetz L, Conway A, Wodicka L, Wolfsberg TG, Gabrielian AE, Landsman D, Lockhart DJ and Davis RW: A genome-wide transcriptional analysis of the mitotic cell cycle. Mol Cell 2: 65-73, 1998.

42. Lichtinghagen R, Musholt PB, Lein M, Römer A, Rudolph B, Kristiansen G, Hauptmann S, Schnorr D, Loening SA and Jung K: Different mRNA and protein expression of matrix metalloproteinases 2 and 9 and tissue inhibitor of metalloproteinases 1 in benign and malignant prostate tissue. Eur Urol 42: 398-406, 2002.

43. Chen G, Gharib TG, Huang CC, Taylor JM, Misek DE, Kardia SL, Giordano TJ, Iannettoni MD, Orringer MB, Hanash SM and Beer DG: Discordant protein and mRNA expression in lung adenocarcinomas. Mol Cell Proteomics 1: 304-313, 2002.

44. Glickman $\mathrm{MH}$ and Ciechanover A: The ubiquitin-proteasome proteolytic pathway: Destruction for the sake of construction. Physiol Rev 82: 373-428, 2002.

45. Pratt JM, Petty J, Riba-Garcia I, Robertson DH, Gaskell SJ, Oliver SG and Beynon RJ: Dynamics of protein turnover, a missing dimension in proteomics. Mol Cell Proteomics 1: 579-591, 2002

46. Langlois MR and Delanghe JR: Biological and clinical significance of haptoglobin polymorphism in humans. Clin Chem 42: 1589-1600, 1996

47. Gogos CA, Drosou E, Bassaris HP and Skoutelis A: Pro-versus anti-inflammatory cytokine profile in patients with severe Sepsis: A marker for prognosis and future therapeutic options. J Infect Dis 181: 176-180, 2000.

48. Wang CH, Gee MJ, Yang C and Su YC: A new model for outcome prediction in intra-abdominal sepsis by the linear discriminant function analysis of IL-6 and IL-10 at different heart rates. J Surg Res 132: 46-51, 2006.

49. Acosta C and Davies A: Bacterial lipopolysaccharide regulates nociceptin expression in sensory neurons. J Neurosci Res 86: 1077-1086, 2008

50. Andoh T, Itoh M and Kuraishi Y: Nociceptin gene expression in rat dorsal root ganglia induced by peripheral inflammation. Neuroreport 8: 2793-2796, 1997.

51. Itoh M, Takasaki I, Andoh T, Nojima H, Tominaga $M$ and Kuraishi Y: Induction by carrageenan inflammation of prepronociceptin mRNA in VR1-immunoreactive neurons in rat dorsal root ganglia. Neurosci Res 40: 227-233, 2001.

52. Williams JP, Thompson JP, Young SP, Gold SJ, McDonald J, Rowbotham DJ and Lambert DG: Nociceptin and urotensin-II concentrations in critically ill patients with sepsis. Bri J Anaesth 100: 810-814, 2008.

53. Dellinger RP, Levy M, Rhodes A, Annane D, Gerlach H, Opal SM, Sevransky JE, Sprung CL, Douglas IS, Jaeschke R, et al: Surviving sepsis campaign: International guidelines for management of severe sepsis and septic shock, 2012. Intens Care Med 39: 165-228, 2012, 2013. 